OPEN ACCESS

Edited by:

Zezhi Li,

Shanghai JiaoTong University, China

Reviewed by:

Graziella Mangone, INSERM CIC1422 CIC Pitié

Neurosciences, France Francesco Ernesto Pontieri, Sapienza University of Rome, Italy

*Correspondence: Yun-Cheng Wu

yunchw@medmail.com.cn

tThese authors have contributed equally to this work

Specialty section:

This article was submitted to Aging Psychiatry,

a section of the journal

Frontiers in Psychiatry

Received: 30 November 2020 Accepted: 19 January 2021

Published: 09 February 2021

Citation:

Zhang $J-F$, Wang $X-X$, Feng $Y$ Fekete $R$, Jankovic J and Wu $Y-C$ (2021) Impulse Control Disorders in Parkinson's Disease: Epidemiology,

Pathogenesis and Therapeutic

Strategies.

Front. Psychiatry 12:635494. doi: 10.3389/fpsyt.2021.635494

\section{Impulse Control Disorders in Parkinson's Disease: Epidemiology, Pathogenesis and Therapeutic Strategies}

\author{
Jun-Fang Zhang ${ }^{1 \dagger}$, Xi-Xi Wang ${ }^{1,2 \dagger}$, Ya Feng ${ }^{1 \dagger}$, Robert Fekete ${ }^{3}$, Joseph Jankovic ${ }^{4}$ and \\ Yun-Cheng $\mathrm{Wu}^{1 *}$ \\ 1 Department of Neurology, Shanghai General Hospital, Shanghai Jiao Tong University School of Medicine, Shanghai, China, \\ ${ }^{2}$ Shanghai General Hospital of Nanjing Medical University, Nanjing, China, ${ }^{3}$ Department of Neurology, New York Medical \\ College, New York, NY, United States, ${ }^{4}$ Department of Neurology, Baylor College of Medicine, Houston, TX, United States
}

Impulse control disorders (ICDs) in Parkinson's disease (PD) are aberrant behavior such as pathological gambling, hypersexuality, binge eating, and compulsive buying, which typically occur as a result of dopaminergic therapy. Numerous studies have focused on the broad spectrum of ICDs-related behaviors and their tremendous impact on patients and their family members. Recent advances have improved our understanding of ICDs. In this review, we discuss the epidemiology, pathogenesis and treatment of ICDs in the setting of PD.

Keywords: Parkinson's disease, impulse control disorders, dopaminergic drugs, pathological gambling, hypersexuality, binge eating, compulsive buying

\section{HIGHLIGHTS}

- Impulse control disorders are increasingly recognized as highly impactful features in patients with Parkinson's disease.

- Dopamine receptor agonists are the strongest risk factors.

- The mechanism of impulse control disorders is still not well-understood but the dopamine reward system and inhibition systems are clearly involved.

\section{INTRODUCTION}

Parkinson's disease (PD) is the second most common neurodegenerative disorder (1). Chronic use of dopaminergic medications in PD is associated with motor and non-motor side effects such as dyskinesias, and impulse control disorders (ICDs) (2). Motor symptoms of PD have traditionally been the major focus of research, but non-motor symptoms, especially ICDs have gradually attracted great attention because of their tremendous impact on patients and their family (3-5). In general, ICDs refer to pathological gambling (PG), hypersexuality, binge eating, and compulsive buying. The core features of ICDs include repetitive or compulsive behavior, reduced control over these behavior, and pleasurable feeling while carrying out the behavior (4). 
PG is defined as persistent and recurrent problematic gambling behavior as indicated by features such as increasing amounts of money, restlessness or irritability when cutting down, failing to control the behavior, preoccupation with gambling, lying to others, and so on (at least four criteria required). However, based on neuropsychiatric and possibly pathophysiological features, PG is currently considered as typical example of behavioral addiction and included in the diagnostic category of "substance-related and addictive disorders" according to DSM-5 $(6,7)$. Hypersexuality means increasing preoccupation with sexual thought, excessive sexual needs, increased use of pornography and self-stimulatory behavior, seeking out prostitutes, engaging in exhibitionism and paraphilia (8). Binge eating involves uncontrollable consumption of a large amount of food, which results in harmful gain of weight (9). Compulsive buying or shopping can be defined as irresistible excessive buying that can lead to psychological consequences and financial debt (10).

In addition to the ICD, there are also some ICD-related disorders (ICRDs), such as Dopamine dysregulation syndrome (DDS) and punding. DDS implies repeated, unnecessary, or sometimes deleterious daily intake of dopaminergic agents far more than the dosage required for treatment of objective motor impairment, leading to severe dyskinesia, euphoria, aggressivity, hallucination, confusion, or frank psychosis (11). Punding is a term that was coined originally to describe complex prolonged, purposeless, and stereotyped behavior in chronic amphetamine users (12). It shares similarities with addictive behavior and involves psychiatric symptoms relating to dopamine system (13).

Besides the classic ICDs symptoms there are many other ICDs-related behavioral problems including reckless driving (14), impulsive smoking (15), compulsive singing (11), tattooing (16), stealing (17), pet killing (18), and zoophilia (19) (Table 1). The wide clinical spectrum of ICDs symptoms necessitates careful monitoring of behavior when patients are taking dopaminergic drugs. As the researches indicated, dopamine, have been known to have a strong association with ICDs (20).

This review mainly focuses on the ICDs in PD patients from the point of epidemiology, pathogenesis and therapeutic strategies.

\section{THE EPIDEMIOLOGY OF ICDS}

The prevalence of ICDs in PD patients using dopamine replacement therapy (DRT) varied from 3.5 to $43 \%$ (21-23). Dopamine receptor agonist (DA) treatment in PD is associated with 2-3.5-fold increased odds of having ICDs compared with patients without DA treatment (24). Estimated incidence of ICDs in PD patients increases with time especially in those on DRT (23). In one longitudinal study, the 5-year cumulative incidence

\footnotetext{
Abbreviations: ICDs, Impulse control disorders; PD, Parkinson's disease; PG, Pathological gambling; DDS, Dopamine dysregulation syndrome; DRT, Dopamine replacement therapy; DAs, Dopamine agonists; ACC, anterior cingulate cortices; OFC, orbitofrontal cortex; VTA, ventral tegmental area; DAT, Dopamine transporter; RBD, Rapid eyes movement sleep behavior disorder; STN, Subthalamic nucleus; DBS, Deep brain stimulation; TMS, Transcranial magnetic stimulation.
}

of ICDs was about $46 \%$ (25). A study showed that $17.5 \%$ PD subjects resulted positive with ICDs before starting treatment, indicating the need for a detailed behavioral assessment before dopaminergic therapy (26).

ICD is probably much more frequent in $\mathrm{PD}$ than previously reported as patients often underestimate the presence and severity of ICD symptoms (27). This is in part due to lack of insight, but also as a defense mechanism with denial and minimization of symptoms on a background of feelings of shame or guilt. Some patients with ICDs may have a relative lack of empathy and do not perceive any stress from their aberrant behavior, despite marked concerns by family members and friends (28).

\section{THE RISK FACTORS OF ICDs}

\section{Dopaminergic Drugs and ICDs}

Although the frequency of impulsivity and compulsive behavior in PD patients before initiation of dopamine receptor agonists is similar to the frequency in healthy control, it is conceivable that dopamine receptor agonists may turn impulsive personality traits into clinically disorders (26). Specifically, affinity of pramipexole and ropinirole for the D3 receptors is much greater than the D2 receptor (100 and 25 times, respectively) as well as for D1 receptor (>1,000 and 300 times, respectively) (29, 30). Other dopamine agonists commercially available in only some countries such as piribedil may also lead to ICDs (31). At the same time, the oral dopamine agonists (pramipexole and ropinirole) have been found to have a greater risk for causing ICDs than the transdermal dopamine agonist rotigotine (29), which might be partially explained by the theory that transdermal delivery bypasses erratic gastric emptying and it may avoid other changes in gastrointestinal motility, leading to the stability of plasma level (29). In a post-hoc analysis about PD treated with rotigotine, although no definite conclusion can be reached on any doseresponse relationship between rotigotine and ICDs, the incidence of ICDs appeared to increase with the dosage increase (25), as increased with longer exposure to rotigotine and recommend active surveillance with increased duration of treatment and dose reduction when ICDs are present (32).

In addition to dopamine agonists, levodopa, particularly in high dosages, has been also associated with ICDs (24). In patients taking dopamine agonist, concurrent levodopa usage is reported to increase the odds of ICDs by $\sim 50 \%$ (24). This multi-center study indicated that there is no association with higher dopamine agonists dose but a link with higher levodopa dose with ICDs, suggesting an intrinsic role for levodopa (33). And also, patients with PD treated by levodopa show ICDs more frequently and more severely than patients without levodopa, thereby suggesting the levodopa's significance in a way (34).

Antidepressants and sleep inducers are also significant predictors for individual ICD (35). Aripiprazole, an antipsychotic drug with partial dopamine agonist properties, has been reported to be associated with ICDs especially pathological gambling (36). It has high affinity for the D3 receptor besides regarded as a D2 agonist. The ICD symptoms resolved completely with its cessation according to reports (36). 
TABLE 1 | Rare ICD symptoms in Parkinson's disease.

\begin{tabular}{|c|c|c|c|c|c|}
\hline Symptoms & $\begin{array}{l}\text { Age (yr) and } \\
\text { sex }\end{array}$ & $\begin{array}{l}\text { Course of PD } \\
\text { (yr) }\end{array}$ & Describes & $\begin{array}{l}\text { Medicine (peak } \\
\text { dose) }\end{array}$ & Source \\
\hline Reckless driving & $\begin{array}{l}65, \text { male; } \\
70, \text { male }\end{array}$ & $\begin{array}{l}9 \\
20\end{array}$ & $\begin{array}{l}\text { Impairment in driving } \\
\text { performance associated } \\
\text { with risk-seeking, including } \\
\text { reckless high-speed } \\
\text { driving. }\end{array}$ & L-dopa(-) & (14) \\
\hline Impulsive smoking & 63 , male & 7 & $\begin{array}{l}\text { Urge to smoke. Pramipexol } \\
\text { was discontinued and the } \\
\text { abnormal symptoms } \\
\text { disappeared. However, } \\
\text { with switching to ropinirole, } \\
\text { impulsive smoking } \\
\text { developed again. }\end{array}$ & $\begin{array}{l}\text { Pramipexol(6 } \\
\mathrm{mg} / \mathrm{d}) / \text { Ropinirole } \\
\text { extended release }(12 \\
\mathrm{mg} / \mathrm{d})\end{array}$ & (15) \\
\hline Compulsive singing & $\begin{array}{l}\text { 70, Female; } \\
\text { 71, Male }\end{array}$ & $\begin{array}{l}9 \\
5\end{array}$ & $\begin{array}{l}\text { Urge to sing repeatedly the } \\
\text { same song. }\end{array}$ & $\begin{array}{l}\text { L-dopa(1,268LEU); } \\
\text { L-dopa(634 LEU) }\end{array}$ & (11) \\
\hline Tattooing & 50, Male & - & $\begin{array}{l}\text { Got tattooed seven times } \\
\text { in } 6 \text { months and planned to } \\
\text { make five others. }\end{array}$ & $\begin{array}{l}\text { Pramipexol extended } \\
\text { release } 1.05 \mathrm{mg} / \mathrm{d} \\
\text { and rasagiline } 1 \mathrm{mg} / \mathrm{d}\end{array}$ & (16) \\
\hline Stealing & 48, Female & - & Impulsive stealing. & Pramipexol (-) & $(17)$ \\
\hline Pet killing & 33, Male & - & $\begin{array}{l}\text { Compulsive behavior of } \\
\text { adopting and killing cats. }\end{array}$ & $\begin{array}{l}\text { Pramipexol (4.5 } \\
\mathrm{mg} / \mathrm{d})\end{array}$ & (18) \\
\hline Zoophilia & 58, Male & 20 & $\begin{array}{l}\text { Attempting to have sexual } \\
\text { intercourse with a female } \\
\text { family dog. }\end{array}$ & Pramipexol(8 mg/d) & (19) \\
\hline
\end{tabular}

$P D$ indicates parkinson's disease. LEU indicates $L$-dopa equivalent units.

In addition to that, studies have failed to find correlation between ICDs and severity of levodopa-related motor fluctuations $(37,38)$. There were no differences between PD with ICD and PD without ICDs in terms of LID exhibited by DA dose or scores on UPDRS part IV, mania, impulsive choice, alcohol use, or current or former smoking (39).

\section{Non-Medication Related Risk Factors Demographic Risk Factors}

According to current research, many demographic factors participate in the development of ICDs in PD. For example, age, gender, and personality traits. Young age at PD onset is one of most established independent risk factors for ICDs in PD (40). Compared to patients without ICDs, ICDs patients were much younger $(21,24,25,29,41,42)$, which can be partly explained by that younger patients are more likely to be prescribed taking dopamine agonists. However, the age effect remains after controlling dopamine agonists exposure $(24,43)$. Gender difference may contribute to the different subtypes of ICDs. Overall, ICDs increased over time in a more pronounced way in men compared to women (25). Hypersexuality is more prevalent in males while binge eating and buying are more common in women $(24,42,43)$. Moreover, male, unmarried, personal or family history of smoking, gambling, drug or alcohol addiction, pre-existent or current symptoms of depression or anxiety and personality traits such as impulsiveness and novelty seeking behaviors are also risk factors of ICDs (4, 37, 41, 42, 4446). These findings suggest that multiple elements including neurobiological, environmental, genetic factors all contribute to the development of ICDs (24). Furthermore, there are many other personal risk factors, such as depression, anxiety, aggression, irritability, obsessive-compulsive traits, impulsivity traits, novelty seeking traits, and alexithymia (41, 47-50). The inclusion of these factors in the neuropsychiatric assessment of patients with PD may help identify patients at risk for ICDs.

\section{Symptomatically Related Risk Factors}

The duration of disease or medicine was correlated with ICDs in PD (40). Then the rapid eye movement sleep behavior disorder (RBD) in PD with ICDs is also worth of concern. Actually, whether RBD is a risk factor for ICDs in PD is controversial. Baig et al. (51) recruited 921 cases of PD and screened positive for ICDs at each visit. After statistics, they found that RBD is not associated with increased ICD risk. Another clinical trial involved 401 newly diagnosed PD patients, evaluated ICD behaviors annually and finally revealed that probable RBD is not clearly associated with ICDs in early PD (52). However, a meta-analysis included 10 studies involving 2,781 PD patients drew a conclusion that RBD was associated with a more than 2-fold higher risk of developing ICBs (OR 2.12, $P<0.01$ ) (53), reminding us that $\mathrm{RBD}$ in $\mathrm{PD}$ is confirmed to be a risk factor for impulsive-compulsive behaviors. Hence, more research is needed to explore the role RBD played in PD with ICDs.

\section{Genetic Risk Factors}

There have been studies focusing on DNA polymorphisms of impulsive and compulsive behavior and additive behaviors in decades. A larger number of SNPs in dopaminergic (DRD1 
rs 265981, DDC rs 3837091 and rs 1451375, D3Rp.S9G) glutamatergic, serotonergic and opioid neurotransmitter system have been reported as candidates that improved predictability of ICDs when compared with clinical risk factors (54-56). We here cite certain findings that have strong relationship with ICDs. A study indicated that carriage of either AA genotype of DRD3 or CC genotype of GRIN2B was identified as an independent risk factor for ICDs. Furthermore, variants of DRD3 p.S9G and GRIN2B c.366C $>\mathrm{G}$ may be associated with ICDs in PD (57). In another study, besides GRIN2B (rs7301328), DRD1 (rs4532 and rs4867798), and DRD2/ANKK1 (rs1800497) increase risk for developing ICDs (58). Polymorphism of DRD4 7 -allele also associated with $\operatorname{ICDs}(59,60)$. In addition, a study supported a possible contribution of genetic variation in the HTR2A (serotonin $2 \mathrm{~A}$ receptor gene) to the susceptibility of ICDs in PD patients, with the T allele, which is presumably linked to higher receptor expression, increasing the risk by 2.8 and 6.9 times in CT and TT carriers (61). More recently, DRD3 p.Ser9Gly (rs6280) CT genotype was proved to be associated with PD patients in Indian population (62). Moreover, with the suggestive association between the opioid receptor gene (OPRM1) and ICDs in PD, the researchers bring potential new insights to the understanding of molecular mechanisms of ICDs (63).

A multicenter case-control study showed that specific subtypes of ICDs, such as compulsive shopping, binge eating and punding, had high frequency and were more severe in PD patients with Parkin mutation compared with nonParkin mutation (39). The possible explanation was related to neurodegeneration of frontal-striatal-limbic structures (64). In addition, gray matter volume of caudate nuclei, which is involved in reward and stimulus-reinforcement association learning, decreases in PD patients with Parkin mutation (65).

Comparing with single genetic variants, multiple gene interactions may play a more important role. Using candidate genetic multivariable pane, Kraemmer et al. conducted an interesting study to estimate ICD heritability in PD patients, which included several transmitter systems such as dopamine, serotonin, and norepinephrine genes. They found a substantial $11-16 \%$ increase in ICD behavior predictability compared to examining clinical variables alone. In addition, in 13 candidate variants, OPRK1, HTR2A and DDC genotypes were the strongest genetic predictive factors and OPRK1 polymorphism rs702764 significantly predicted incident of ICD behavior. Hence, they suggested the potential for developing clinical-genetic models to identify PD patients at increased risk of developing ICD and further guide treatments (66).

Although polymorphisms of dopaminergic genes are not considered as the strongest risk factor for developing ICDs in $\mathrm{PD}$ patients at present, further research in the genetic susceptibility will explain the reason why some patients taking low doses of dopaminergic drugs still develop ICDs. Genetic studies can enlarge the understanding of ICDs from pathogenesis to therapy.

\section{NEUROPSYCHOLOGICAL STUDIES IN ICDs}

Various neuropsychological studies have found that ICDs are associated with frontal/executive dysfunctions (67-70). Imbalance of the frontal-striatal circuits which manifested with cognitive dysfunction was considered to be associated with ICDs (71). One study showed that pathological gambling patients performed significantly worse than non-pathological gambling patients in PD on cognitive tasks that evaluated visuo-spatial long-term memory and several frontal lobe functions (68). And PG relates to reward-based decision-making, which is a major topic of behavioral psychology. Clinical neuropsychologists have been using Iowa Gambling Task to evaluate financial risk attitude $(72,73)$. More straightforward behavioral economics task has been tested. Another study indicated that ICDs patients in PD had poorer working memory performance than either the control or PD patients without ICDs (70). A study found that hypersexuality is associated with prefrontal and memory dysfunctions, whereas pathological gambling and compulsive eating seem to be related to only frontal dysfunction (67).

However, there were several studies considering no difference in frontal executive dysfunction on neuropsychological testing between ICDs and non-ICDs patients in PD (73-78), which suggested that executive dysfunction may contribute to ICD behavior, but is not a necessary component (76). A long-term study investigating the progression of cognitive decline in ICDs patients compared with PD patients without ICDs showed that ICDs patients were not with greater cognitive impairment or executive dysfunction, but rather show relatively lower cognitive decline over time. Drug-induced overstimulation of relatively preserved prefrontal cognitive functions may impair the topdown inhibitory control contributing to ICDs (77). These finding still needs to be verified.

Intertemporal choices, decisions between options available at different times, are commonly applied in impulsivity-related studies. The presence of impulsivity trait in intertemporal choices is usually suggested by a strong preference for small immediate rewards over large delayed ones (79). Temporal discounting is a phenomenon that the subjective valuation of reward declines with delay. In studies using intertemporal choice task, investigators found that dopamine agonist use was associated with greater choice impulsivity in ICDs patients compared to PD. It is suggested that there has been a Ushaped relationship between dopamine activity and temporal discounting (80). Dopamine agonists are associated with a greater discounting of larger delayed rewards, therefore contributing to impulsive choices (69).

\section{THE PATHOGENESIS OF ICDS}

The mechanism of ICDs is not well-understood. Yet based on animal and clinical researches, the dopaminergic system has been strongly implicated. There are three main dopaminergic pathways in central nervous systems (CNS): (a)the nigrostriatal 


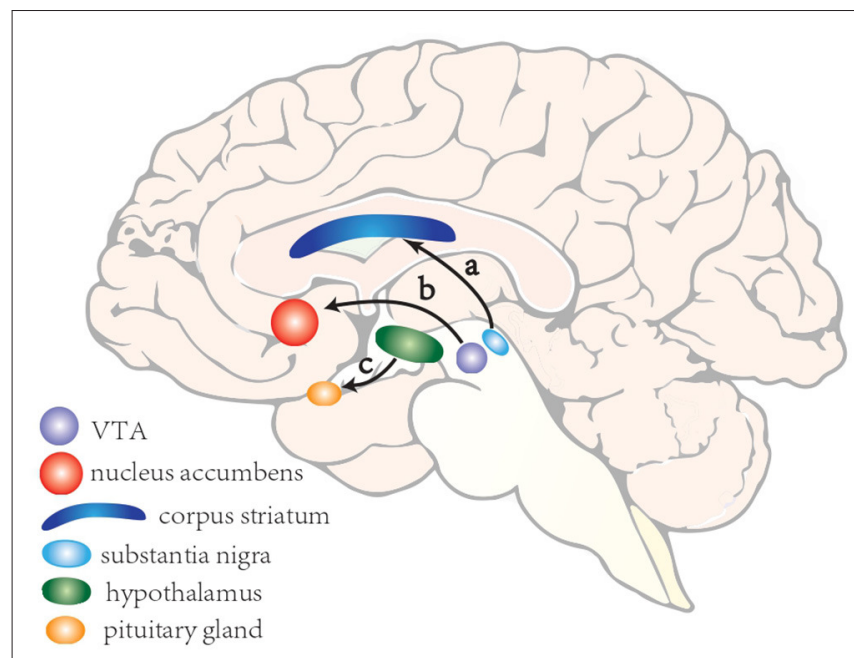

FIGURE 1 | A schematic illustration of three main dopaminergic pathways in central nervous systems. (a) the nigrostriatal pathway consisting of cell bodies in the substantia nigra whose axons terminate in the corpus striatum; (b) the mesocorticolimbic pathway (also known as the reward system), whose cell bodies are situated in the ventral tegmental area and whose axons project to parts of the limbic system; and (c) the tuberoinfundibular pathway, whose cell bodies are found in the ventral hypothalamus and project to the median eminence and pituitary gland.

pathway consisting of cell bodies in the substantia nigra (SN) whose axons terminate in the corpus striatum; (b) the mesocorticolimbic pathway (also known as the reward system), whose cell bodies are situated in the ventral tegmental area and whose axons project to parts of the limbic system; and (c) the tuberoinfundibular pathway, whose cell bodies are found in the ventral hypothalamus and project to the median eminence and pituitary gland (Figure 1). Of the three dopaminergic pathways the mesocorticolimbic system seems to play a key role in the reward system, whose main components include nucleus accumbens, amygdala, hippocampus, anterior cingulate and orbitofrontal cortex (81).

Dopamine, as a modulator of risk behavior along the mesocorticolimbic pathway, plays an important role in reinforcement of learning. It signals the difference between predicted and experienced reward, and is also involved in shaping behavior to maximize reward and avoid punishment (82). Normally, in anticipation of a reward or when receiving an unexpected reward, phasic release of dopamine from the ventral tegmental area (VTA) to the nucleus accumbens occurs (83). In contrast, phasic suppression of dopamine occurs when an expected reward is not received (83). Contingencies would result in decreasing activation of the mesocorticolimbic dopaminergic system leading to adaptive behavior and shifting from one pattern to a more appropriate action (84) (Figure 2A). In $\mathrm{PD}$, excessive doses of dopamine, dopamine reuptake impairment or stimulation on postsynaptic dopamine receptors by dopaminergic agonists may shift this normal physiologic response and facilitate the appearance of ICDs $(57,82)$. ICDs patients exhibit reduced ability to learn from negative events and

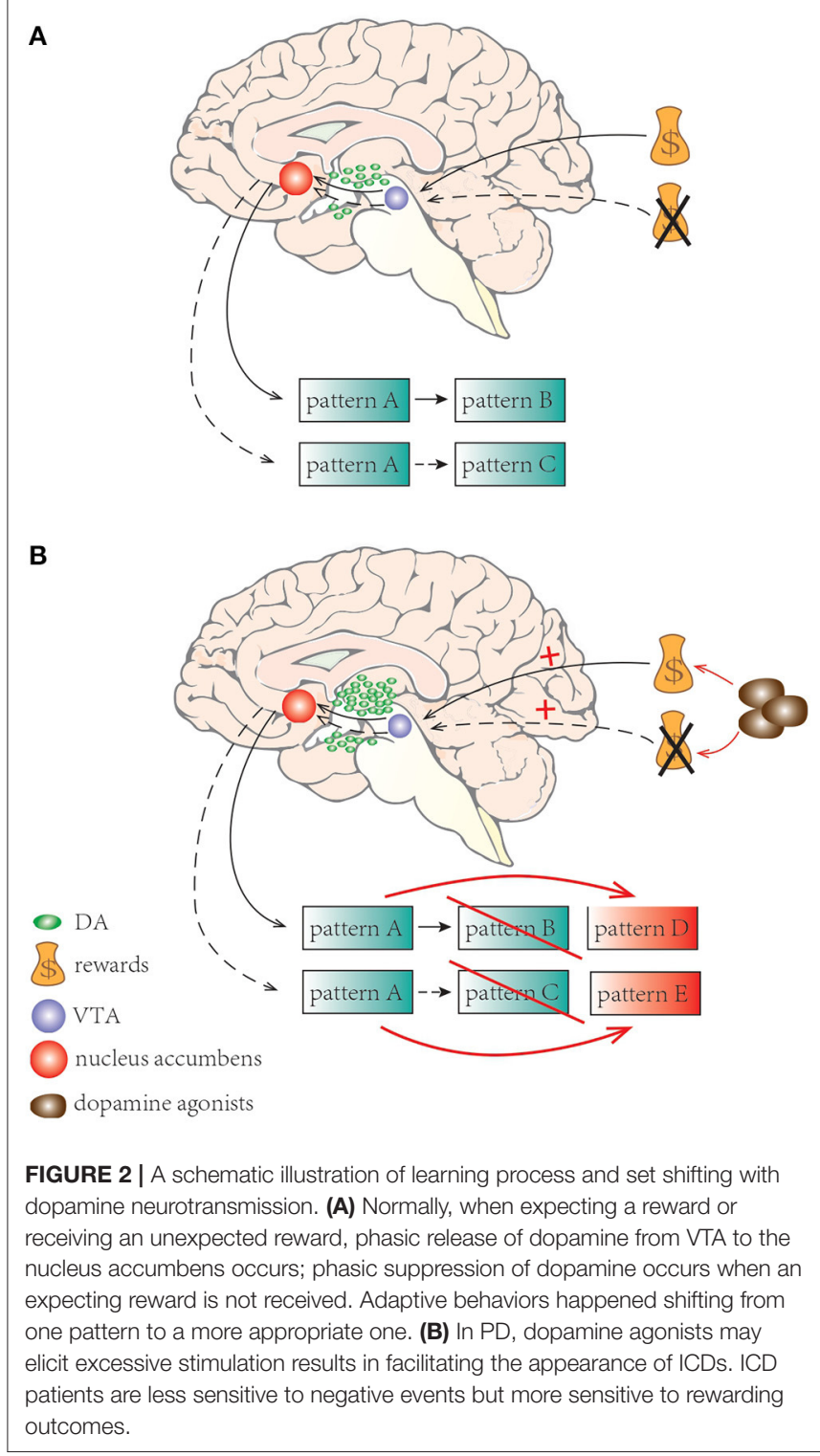

they usually underestimate the adverse consequence of stimuli with punishment, yet they are more sensitive to rewarding outcomes (85) (Figure 2B).

There are several observations relevant to reward system and ICDs that are worth highlighting. First, the usual pleasurable stimuli such as food can induce tonic dopamine response in the outer shell of the nucleus accumbens. Second, dopamine auto-receptors in SN provide feedback to regulate synaptic dopamine concentration. Third, the orbitofrontal and anterior cingulate cortices (ACC) are involved in the top-down control, evaluating the reward and directing a suitable reaction, thus making adjustments for optimizing future choices (86). Finally, the prefrontal cortex exerts inhibitory influence to "balance" the system (Figure 3). All these components are working together to help individuals adapt to their environment.

PD is associated with a neurodegenerative process that involves mesocorticolimbic network, but there is paucity of data 
A
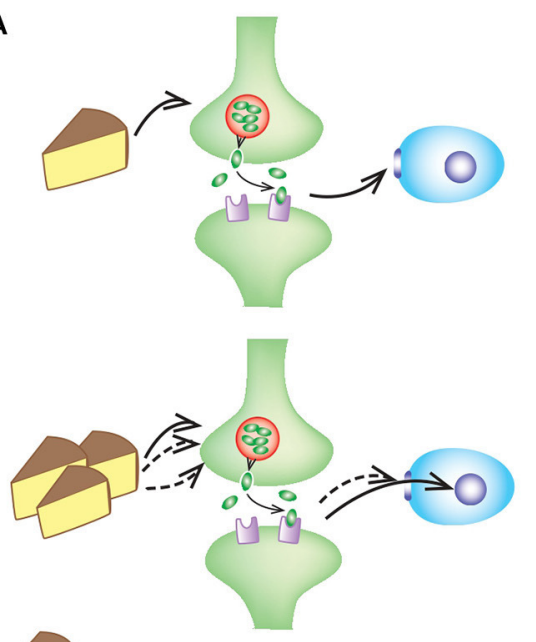

food

DA

O nucleus accumbens
B

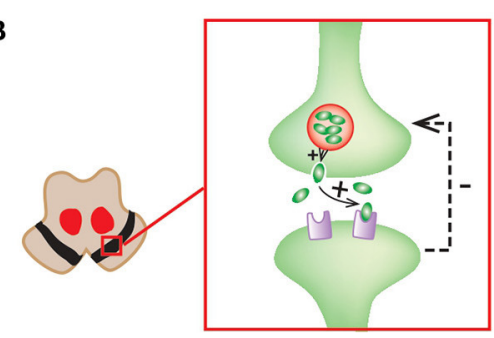

C

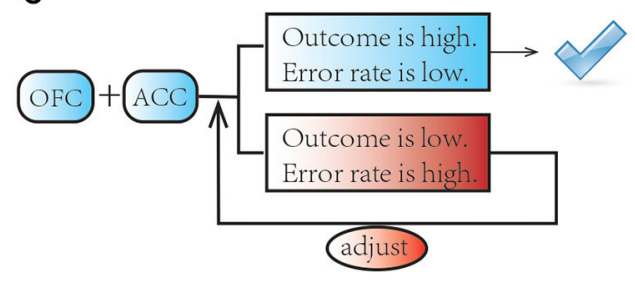

FIGURE 3 | A schematic illustration of mesocorticolimbic network and reward system. (A) Standard stimuli (e.g., food) motivate tonic dopamine response in the outer shell of the nucleus accumbens; repeated stimuli induce habitation with the response shifting to its core. (B) In substantia nigra, dopamine autoreceptors offer feedback to regulate synaptic dopamine concentrations. (C) The OFC and ACC make adjustments for optimizing future choices and balance the system.

linking abnormalities of this network to ICDs. One study, using volumetric magnetic resonance imaging (MRI) technique, found that amygdala volume was greater in PD patients with ICDs than those without ICDs, but similar to health control subjects (64). Since amygdala is important in processing both positive and aversive emotional inputs, relatively preserved amygdala is needed for the expression of ICDs $(87,88)$. Another study showed that ICDs patients have a thicker cortex in certain limbic regions especially in ACC and orbitofrontal cortex, which may be linked to increased impulsivity and behavioral disinhibition (89). In addition, this study demonstrated positive correlation between the ACC thickening and ICD severity (89). Moreover, a wholebrain diffusion-tensor MRI study found white-matter integrity in the reward system is relatively preserved in ICDs-PD patients compared to PD patients without ICDs (90). A BOLD fMRI study observed that PD patients with ICDs had elevated network connectivity in the mesocorticolimbic network (91).

The mesocorticolimbic reward system plays an important role in the development and maintenance of addictive behavior. The reason for male preponderance in patients exhibiting this behavior is still unclear, but some imaging studies have suggested that males have a stronger functional connectivity in the reward mesocorticolimbic system than females $(29,92)$. Thus, the relative preservation of neural integrity in mesocorticolimbic network and the intact reward-processing circuits are thought to increase risk for ICDs in PD patients treated with dopaminergic medications (90).

In addition to the reward system, ICDs are also involved in the inhibition system. One fMRI study showed impairment in response-inhibition abilities in ICDs patients (93). The observation found that the rostral portion of the corpus callosum in ICDs patients is thinner compared to healthy control. And it has been interpreted to indicate that there might be some disconnection in the inhibitory system normally mediated by the corpus callosum, leading to behavioral disinhibition and ICDs. The normal inhibitory mechanisms may be further disrupted by treatment with dopaminergic drugs which may explain why some PD patients become vulnerable and experience loss of impulse control (disinhibition) and finally results in the development of ICDs (94). In support of this hypothesis is the finding that pramipexole decreases the interaction between the nucleus accumbens and prefrontal cortex, which might lead to a reduction of normal prefrontal inhibitory control of impulses (95). Thus, dopamine agonists presumably act by suppressing the inhibitory system and elicit a response bias toward impulsive choices (96).

Dopamine agonists improve motor symptoms in PD patients through their effects on the dorsal striatum, but they also activate the ventral striatum and the mesolimbic pathway (97). The brain activity in ventral striatum can be separated spatially and temporally into signals correlated with risk and reward expectation which are both the foundation of decision-making (98). In addition to the involvement of the striatum in ICDs, several studies have implicated the ventral pallidum in the modulation of hedonic responses to rewards (99). Using arterialspin-labeling MRI, increased cerebral blood flow to ventral striatum in ICDs patients had been substantiated in response to dopamine agonists, which indicated that dopamine agonists can 
augment mesocorticolimbic network activity in ICDs patients (100). The function of the orbitofrontal cortex (OFC) is critical in understanding the mechanisms of rewards or punishments $(65,101)$. The OFC may be activated by stimuli from rewardrelated memories or environment which then induces a strong sense of urge with or without activation of the nucleus accumbens (102). While the medial OFC engages in reward-based decisionmaking the lateral OFC is associated with the punishment-based decision-making (101). The role of OFC in ICDs is supported by studies that have found dysfunction of impaired longterm memory and frontal lobe functions in patients exhibiting pathological gambling compared to control (68). Other studies have found evidence that frontal lobe dysfunction facilitates the onset and persistence of pathological gambling in PD (103).

\section{THERAPEUTIC STRATEGIES FOR ICDS}

In ICDs patients with PD, caregivers suffer huge burden from mental stress specifically on spousal safety. ICDs are associated with high rate of separation and divorce, child abuse, and neglect $(4,104,105)$. It is important to recognize the disease and treat it without delay.

As discussed above, ICDs are considered to have strong relationship with dopamine agonists. Decreasing or even withdrawing dopamine agonists is usually the first choice for clinicians. For PD patients who have developed ICDs on account of dopamine agonist treatment, they will get remission significantly after decreasing dosages. One longitudinal study suggested that ICDs resolved after 1 year in about $50 \%$ of the patients who stopped dopamine agonists and continued to improve (25). Patients can increase levodopa dosage instead to avoid worsening in motor symptoms (106). However, treatment is still challenging, as patients may experience dopamine agonist withdrawal syndrome (107-109).

Considering the benefit from reducing dose of dopamine agonists such as pramipexole or ropinirole, it is recommended that temporary replacement of pramipexole by bromocriptine instead may relieve or reverse the ICDs while the D2 stimulation needed for motor symptoms are still maintained (95).

Subthalamic nucleus (STN) deep brain stimulation (DBS) as a treatment for ICDs is considered a controversial method according to reported literature. Compared to patients without ICDs, ICDs patients exhibited increased proportion of subthalamic neurons responsive to prospective reward and decreased proportion to prospective loss in STN but no in GPi (110). STN-DBS and the following tapering of dopaminergic treatment can change personality traits in PD patients (111). A few studies are in favor of DBS surgery as a treatment for ICDs and even suggest that ICDs may be considered as new indication for STN-DBS $(112,113)$. ICDs patients exhibited a complex outcome after STN-DBS, with a tendency for overall reduction but with several factors affecting its effect (114). It is believed that effective management of medication and correct stimulation parameters may explain these results better than previous literature. Successful surgery allows a marked decrease of total dopaminergic medication. The STN stimulation may also have specific effect on limbic part of the STN (115). In general, fine-tuning of stimulation parameter after DBS surgery, accompanied with drastic reduction of dopaminergic medication are considered as an effective method to give remission to ICDs patients especially advanced subgroup $(116,117)$. Furthermore, there has been a study indicating that unilateral procedures may be an alternative to bilateral DBS for some patients if they are with asymmetric symptomology (118). Meanwhile, some studies disapprove of using STN-DBS because ICDs may persist or even worsen after DBS surgery (119). Even more, some evidence shows that ICDs may emerge following DBS surgery regardless of unilateral or bilateral DBS (120-122). Stimulation by DBS might sensitize the brain to the impulsive behaviors induced by dopamine agonists, especially in patients with addictive behavior history (121). Besides, stimulation with electrode contacts located mainly within the sensorimotor territory can result in spread of current to limbic and associative area (123). Failed surgery, with misplaced electrodes outside the STN, would result in failure to reduce dopaminergic medication or even causing new onset of dopaminergic treatment (112). Stimulation intensity increased too rapidly will elicit ICDs in the same way as dopaminergic treatment (124). Therefore, we should be careful when choosing DBS treatment in clinical practices.

Amantadine, acting as a dopaminergic and glutamatergic modulator, was reported to have great effect on reversing ICD symptoms without aggravating motor function. Amantadine add-on therapy is considered to reduce hypersensitivity in ICDs patients therefore decrease risky choice (125-127). However, amantadine was associated with an increased risk for ICDs in another multicenter study (128).

As ICDs are thought to be linked to oral dopamine agonists, strategies utilizing intrajejunal levodopa which utilize continuous drug delivery may decrease the risk of developing ICDs. This therapy may become a popular treatment of ICDs not only because its positive effect on behavioral disorders but also motor complications $(129,130)$.

Clozapine were reported as a potential treatment for refractory ICDs. Clozapine not only has an effect on dopamine-blocking activity in the limbic system but also has weak antagonistic D3 and high antagonistic D4 activity that makes it capable of adjusting the reward circuit. Besides, N-desmethyloclozapine, the major active plasma metabolite of clozapine, may have an important partial agonist activity on dopamine D2/D3 receptors (131). There have been several cases reporting beneficial responses to clozapine in ICDs patients $(132,133)$.

There has been an emerging method to treat ICDs using transcranial magnetic stimulation (TMS). A study reported that low-frequency repetitive TMS was used to treat four PD patients with punding whose symptoms were reversed magically. TMS deserves more studies to explore the best pattern and more indications (134).

To date, there have been few studies concerning the role of cognitive behavior therapy in ICDs. Okai et al. proved the efficacy of cognitive behavior treatment in ICD patients with PD through a randomized controlled trail. They found the combined treatment of cognitive behavior treatment with medical care was more effective in reducing the severity of ICDs compared 
with medical care alone. The severity of symptom (measured on the Clinical Global Impression (CGI) index) significantly reduced $75 \%$ of the experimental group compared with only $29 \%$ in the control group. The intervention seemed to be also effective in depression and anxiety. Larger and long-term follow up studies are needed to confirm the benefit of cognitive behavior treatment in each subtype of ICDs, and meanwhile assess the cost-effectiveness (135).

In addition to those treatments discussed above, valproate, zonisamide, naloxone, apomorphine, and bromocriptine may also be beneficial in treating $\operatorname{ICDs}(136,137)$. Dopamine agonists with lower D3 selectivity appear to have lower proportion of causing ICDs. Switching to bromocriptine was proposed as a method to mitigate ICDs. More research and clinical trials are needed to explore the best therapeutic strategy.

\section{CONCLUSION}

In conclusion, present studies remind us to pay much attention to non-motor symptoms including ICDs. With rapid advance

\section{REFERENCES}

1. de Lau LM, Breteler MM. Epidemiology of Parkinson's disease. Lancet Neurol. (2006) 5:525-35. doi: 10.1016/S1474-4422(06)70471-9

2. Voon V, Napier TC, Frank MJ, Sgambato-Faure V, Grace AA, RodriguezOroz $M$, et al. Impulse control disorders and levodopa-induced dyskinesias in Parkinson's disease: an update. Lancet Neurol. (2017) 16:238-50. doi: 10.1016/S1474-4422(17)30004-2

3. Weintraub D, Mamikonyan E. Impulse control disorders in Parkinson's disease. Am J Psychiatry. (2019) 176:511. doi: 10.1176/appi.ajp.2018.18040465

4. Ceravolo R, Frosini D, Rossi C, Bonuccelli U. Impulse control disorders in Parkinson's disease: definition, epidemiology, risk factors, neurobiology and management. Parkinsonism Relat Disord. (2009) 15(Suppl. 4):S1115. doi: 10.1016/S1353-8020(09)70847-8

5. Moegle C, Grillon A, Anheim M, Lipsker D, Velter C. Impulse control disorder-linked hypersexuality complicated by disseminated gonococcal infection in a patient with Parkinson's disease. Rev Neurol. (2020) 176:292-3. doi: 10.1016/j.neurol.2019.10.007

6. Nautiyal KM, Okuda M, Hen R, Blanco C. Gambling disorder: an integrative review of animal and human studies. Ann N Y Acad Sci. (2017) 1394:10627. doi: $10.1111 /$ nyas. 13356

7. Goudriaan AE, Yucel M, van Holst RJ. Getting a grip on problem gambling: what can neuroscience tell us? Front Behav Neurosci. (2014) 8:141. doi: $10.3389 /$ fnbeh.2014.00141

8. Lim SY, Evans AH, Miyasaki JM. Impulse control and related disorders in Parkinson's disease: review. Ann N Y Acad Sci. (2008) 1142:85107. doi: 10.1196/annals. 1444.006

9. Nirenberg MJ, Waters C. Compulsive eating and weight gain related to dopamine agonist use. Mov Disord. (2006) 21:524-9. doi: 10.1002/mds. 20757

10. Dittmar H. Compulsive buying-a growing concern? An examination of gender, age, and endorsement of materialistic values as predictors. $\mathrm{Br} J$ Psychol. (2005) 96:467-91. doi: 10.1348/000712605X53533

11. Bonvin C, Horvath J, Christe B, Landis T, Burkhard PR. Compulsive singing: another aspect of punding in Parkinson's disease. Ann Neurol. (2007) 62:5258. doi: 10.1002/ana.21202

12. Evans AH, Katzenschlager R, Paviour D, O'Sullivan JD, Appel S, Lawrence AD, et al. Punding in Parkinson's disease: its relation to regarding to ICDs, mechanisms of ICDs will become gradually clear and specific individual treatment strategies will be applied in the future. Given that ICDs would have terrible impact and consequence on families, patients and their caregivers should be educated in clinical practice. In addition, ICDs in PD patients may also provide a model for better understanding of the neurobiology of addiction.

\section{AUTHOR CONTRIBUTIONS}

$\mathrm{Y}-\mathrm{CW}$ provided the funding support and designed the project. J-FZ, X-XW, and YF searched for literature and wrote the manuscript. Y-CW, RF, and JJ revised the paper. All authors contributed to the article and approved the submitted version.

\section{FUNDING}

This work was partially supported by the grants from the National Natural Science Foundation of China (Nos. 81671251, 81971185). the dopamine dysregulation syndrome. Mov Disord. (2004) 19:397405. doi: $10.1002 / \mathrm{mds} .20045$

13. Pettorruso M, Fasano A, De Risio L, Ricciardi L, Di Nicola M, Martinotti G, et al. Punding in non-demented Parkinson's disease patients: relationship with psychiatric and addiction spectrum comorbidity. J Neurol Sci. (2016) 362:344-7. doi: 10.1016/j.jns.2016.02.016

14. Avanzi M, Baratti M, Cabrini S, Uber E, Brighetti G, Bonfa F. The thrill of reckless driving in patients with Parkinson's disease: an additional behavioural phenomenon in dopamine dysregulation syndrome? Parkinsonism Relat Disord. (2008) 14:257-8. doi: 10.1016/j.parkreldis.2007.04.006

15. Bienfait KL, Menza M, Mark MH, Dobkin RD. Impulsive smoking in a patient with Parkinson's disease treated with dopamine agonists. J Clin Neurosci. (2010) 17:539-40. doi: 10.1016/j.jocn.2009.09.001

16. Maltete D, Le Goff F, Ozel G, Lefaucheur R. Tattooing as a symptom of impulse control disorder in a parkinsonian patient with pramipexole. J Clin Psychopharmacol. (2016) 36:736-7. doi: 10.1097/JCP.0000000000000585

17. Clemm von Hohenberg C, Dressing $H$. Stealing as an impulse control disorder associated with pramipexole - a case report from forensic psychiatric practice. Psychiatr Prax. (2017) 44:172-4. doi: 10.1055/s-0043-100024

18. Micheli F, Pellene A, Arcushin D, Calzinari A, Farret MS. Pet killing as a manifestation of impulse control disorder secondary to pramipexol. Clin Neuropharmacol. (2015) 38:55-6. doi: 10.1097/WNF.0000000000000074

19. Raina G, Cersosimo MG, Micheli F. Zoophilia and impulse control disorder in a patient with Parkinson disease. J Neurol. (2012) 259:96970. doi: 10.1007/s00415-011-6270-z

20. Moore TJ, Glenmullen J, Mattison DR. Reports of pathological gambling, hypersexuality, and compulsive shopping associated with dopamine receptor agonist drugs. JAMA Intern Med. (2014) 174:1930-3. doi: 10.1001/jamainternmed.2014.5262

21. Ramirez Gomez CC, Serrano Duenas M, Bernal O, Araoz N, Saenz Farret M, Aldinio V, et al. A multicenter comparative study of impulse control disorder in latin American patients with Parkinson disease. Clin Neuropharmacol. (2017) 40:51-5. doi: 10.1097/WNF.0000000000000202

22. Ambermoon P, Carter A, Hall WD, Dissanayaka NN, O'Sullivan JD. Impulse control disorders in patients with Parkinson's disease receiving dopamine replacement therapy: evidence and implications for the addictions field. Addiction. (2011) 106:283-93. doi: 10.1111/j.1360-0443.2010.03218.x 
23. Smith KM, Xie SX, Weintraub D. Incident impulse control disorder symptoms and dopamine transporter imaging in Parkinson disease. J Neurol Neurosurg Psychiatry. (2016) 87:864-70. doi: 10.1136/jnnp-2015-311827

24. Weintraub D, Koester J, Potenza MN, Siderowf AD, Stacy M, Voon V, et al. Impulse control disorders in Parkinson disease: a cross-sectional study of 3090 patients. Arch Neurol. (2010) 67:589-95. doi: 10.1001/archneurol.2010.65

25. Corvol JC, Artaud F, Cormier-Dequaire F, Rascol O, Durif F, Derkinderen P, et al. Longitudinal analysis of impulse control disorders in Parkinson disease. Neurology. (2018) 91:e189-201. doi: 10.1212/WNL.0000000000005816

26. Antonini A, Siri C, Santangelo G, Cilia R, Poletti M, Canesi M, et al. Impulsivity and compulsivity in drug-naive patients with Parkinson's disease. Mov Disord. (2011) 26:464-8. doi: 10.1002/mds.23501

27. Baumann-Vogel H, Valko PO, Eisele G, Baumann CR. Impulse control disorders in Parkinson's disease: don't set your mind at rest by selfassessments. Eur J Neurol. (2015) 22:603-9. doi: 10.1111/ene.12646

28. Tomei A, Besson J, Grivel J. Linking empathy to visuospatial perspective-taking in gambling addiction. Psychiatry Res. (2017) 250:177-84. doi: 10.1016/j.psychres.2016.12.061

29. Garcia-Ruiz PJ, Martinez Castrillo JC, Alonso-Canovas A, Herranz Barcenas A, Vela L, Sanchez Alonso P, et al. Impulse control disorder in patients with Parkinson's disease under dopamine agonist therapy: a multicentre study. J Neurol Neurosurg Psychiatry. (2014) 85:8404. doi: 10.1136/jnnp-2013-306787

30. Martinez-Castrillo JC. Impulse control disorders in Parkinson's disease: a hard-turning point. J Neurol Neurosurg Psychiatry. (2019) 90:2. doi: 10.1136/jnnp-2018-319375

31. Micheli FE, Giugni JC, Espinosa ME, Calvo DS, Raina GB. Piribedil and pathological gambling in six parkinsonian patients. Arq Neuropsiquiatr. (2015) 73:115-8. doi: 10.1590/0004-282X20140212

32. Antonini A, Chaudhuri KR, Boroojerdi B, Asgharnejad M, Bauer L, Grieger $\mathrm{F}$, et al. Impulse control disorder related behaviours during long-term rotigotine treatment: a post hoc analysis. Eur J Neurol. (2016) 23:155665. doi: $10.1111 /$ ene. 13078

33. Voon V, Fernagut PO, Wickens J, Baunez C, Rodriguez M, Pavon N, et al. Chronic dopaminergic stimulation in Parkinson's disease: from dyskinesias to impulse control disorders. Lancet Neurol. (2009) 8:11409. doi: 10.1016/S1474-4422(09)70287-X

34. Simoni S, Paoletti FP, Eusebi P, Cappelletti G, Filidei M, Brahimi E, et al. Impulse control disorders and levodopa-induced dyskinesias in Parkinson's disease: pulsatile versus continuous dopaminergic stimulation. J Parkinsons Dis. (2020) 10:927-34. doi: 10.3233/JPD-191833

35. Carbunaru S, Eisinger RS, Ramirez-Zamora A, Bassan D, Cervantes-Arriaga A, Rodriguez-Violante M, et al. Impulse control disorders in Parkinson's: sleep disorders and nondopaminergic associations. Brain Behav. (2018) 8:e00904. doi: 10.1002/brb3.904

36. Dhillon R, Bastiampillai T, Cao CZ, Eckert TG, Tibrewal P. Aripiprazole and impulse-control disorders: a recent FDA warning and a case report. Prim Care Companion CNS Disord. (2017) 19:1. doi: 10.4088/PCC.16102003

37. Antonini A, Barone P, Bonuccelli U, Annoni K, Asgharnejad M, Stanzione P. ICARUS study: prevalence and clinical features of impulse control disorders in Parkinson's disease. J Neurol Neurosurg Psychiatry. (2017) 88:317-24. doi: 10.1136/jnnp-2016-315277

38. Storch A, Schneider CB, Wolz M, Sturwald Y, Nebe A, Odin $\mathrm{P}$, et al. Nonmotor fluctuations in Parkinson disease: severity and correlation with motor complications. Neurology. (2013) 80:800-9. doi: 10.1212/WNL.0b013e318285c0ed

39. Morgante F, Fasano A, Ginevrino M, Petrucci S, Ricciardi L, Bove F, et al. Impulsive-compulsive behaviors in parkin-associated Parkinson disease. Neurology. (2016) 87:1436-41. doi: 10.1212/WNL.0000000000003177

40. Giladi N, Weitzman N, Schreiber S, Shabtai H, Peretz C. New onset heightened interest or drive for gambling, shopping, eating or sexual activity in patients with Parkinson's disease: the role of dopamine agonist treatment and age at motor symptoms onset. J Psychopharmacol. (2007) 21:5016. doi: $10.1177 / 0269881106073109$

41. Voon V, Sohr M, Lang AE, Potenza MN, Siderowf AD, Whetteckey J, et al. Impulse control disorders in Parkinson disease: a multicenter case-control study. Ann Neurol. (2011) 69:986-96. doi: 10.1002/ana.22356
42. Vela L, Martinez Castrillo JC, Garcia Ruiz P, Gasca-Salas C, Macias Macias Y, Perez Fernandez E, et al. The high prevalence of impulse control behaviors in patients with early-onset Parkinson's disease: a cross-sectional multicenter study. J Neurol Sci. (2016) 368:150-4. doi: 10.1016/j.jns.2016.07.003

43. Nakum S, Cavanna AE. The prevalence and clinical characteristics of hypersexuality in patients with Parkinson's disease following dopaminergic therapy: a systematic literature review. Parkinsonism Relat Disord. (2016) 25:10-6. doi: 10.1016/j.parkreldis.2016.02.017

44. Wolters E, van der Werf YD, van den Heuvel OA. Parkinson's disease-related disorders in the impulsive-compulsive spectrum. J Neurol. (2008) 255(Suppl. 5):48-56. doi: 10.1007/s00415-008-5010-5

45. Saez-Francas N, Marti Andres G, Ramirez N, de Fabregues O, AlvarezSabin J, Casas M, et al. Clinical and psychopathological factors associated with impulse control disorders in Parkinson's disease. Neurologia. (2016) 31:231-8. doi: 10.1016/j.nrleng.2015.05.008

46. Martini A, Dal Lago D, Edelstyn NMJ, Grange JA, Tamburin S. Impulse control disorder in Parkinson's disease: a meta-analysis of cognitive, affective, and motivational correlates. Front Neurol. (2018) 9:654. doi: 10.3389/fneur.2018.00654

47. Goerlich-Dobre KS, Probst C, Winter L, Witt K, Deuschl G, Moller $\mathrm{B}$, et al. Alexithymia-an independent risk factor for impulsivecompulsive disorders in Parkinson's disease. Mov Disord. (2014) 29:214-20. doi: 10.1002/mds.25679

48. Pontone G, Williams JR, Bassett SS, Marsh L. Clinical features associated with impulse control disorders in Parkinson disease. Neurology. (2006) 67:1258-61. doi: 10.1212/01.wnl.0000238401.76928.45

49. Voon V, Thomsen T, Miyasaki JM, de Souza M, Shafro A, Fox $\mathrm{SH}$, et al. Factors associated with dopaminergic drug-related pathological gambling in Parkinson disease. Arch Neurol. (2007) 64:212-6. doi: 10.1001/archneur.64.2.212

50. Isaias IU, Siri C, Cilia R, De Gaspari D, Pezzoli G, Antonini A. The relationship between impulsivity and impulse control disorders in Parkinson's disease. Mov Disord. (2008) 23:411-5. doi: 10.1002/mds.21872

51. Baig F, Kelly MJ, Lawton MA, Ruffmann C, Rolinski M, Klein JC, et al. Impulse control disorders in Parkinson disease and RBD: a longitudinal study of severity. Neurology. (2019) 93:e675-87. doi: 10.1212/WNL.0000000000007942

52. Fantini ML, Fedler J, Pereira B, Weintraub D, Marques AR, Durif F. Is rapid eye movement sleep behavior disorder a risk factor for impulse control disorder in Parkinson disease? Ann Neurol. (2020) 88:75970. doi: 10.1002/ana.25798

53. Lu HT, Shen QY, Zhao QZ, Huang HY, Ning PP, Wang H, et al. Association between REM sleep behavior disorder and impulsivecompulsive behaviors in Parkinson's disease: a systematic review and meta-analysis of observational studies. J Neurol. (2020) 267:331-40. doi: 10.1007/s00415-019-09588-3

54. Jimenez-Urbieta H, Gago B, de la Riva P, Delgado-Alvarado M, Marin C, Rodriguez-Oroz MC. Dyskinesias and impulse control disorders in Parkinson's disease: from pathogenesis to potential therapeutic approaches. Neurosci Biobehav Rev. (2015) 56:294-314. doi: 10.1016/j.neubiorev.2015.07.010

55. Weintraub D, Claassen DO. Impulse control and related disorders in Parkinson's disease. Int Rev Neurobiol. (2017) 133:679-717. doi: 10.1016/bs.irn.2017.04.006

56. Bhattacharjee S, Talbot JG, Vijayashankar P. Dopamine D3 receptor Ser9Gly variant is associated with impulse control disorders in Parkinson's disease patients. Parkinsonism Relat Disord. (2017) 34:69-70. doi: 10.1016/j.parkreldis.2016.10.021

57. Lee JY, Lee EK, Park SS, Lim JY, Kim HJ, Kim JS, et al. Association of DRD3 and GRIN2B with impulse control and related behaviors in Parkinson's disease. Mov Disord. (2009) 24:1803-10. doi: 10.1002/mds. 22678

58. Zainal Abidin S, Tan EL, Chan SC, Jaafar A, Lee AX, Abd Hamid MH, et al. DRD and GRIN2B polymorphisms and their association with the development of impulse control behaviour among Malaysian Parkinson's disease patients. BMC Neurol. (2015) 15:59. doi: 10.1186/s12883-015-0316-2

59. Comings DE, Gonzalez N, Wu S, Gade R, Muhleman D, Saucier G, et al. Studies of the 48 bp repeat polymorphism of the DRD4 gene in impulsive, 
compulsive, addictive behaviors: Tourette syndrome, ADHD, pathological gambling, and substance abuse. Am J Med Genet. (1999) 88:358-68.

60. Forbes EE, Brown SM, Kimak M, Ferrell RE, Manuck SB, Hariri AR. Genetic variation in components of dopamine neurotransmission impacts ventral striatal reactivity associated with impulsivity. Mol Psychiatry. (2009) 14:60-70. doi: 10.1038/sj.mp.4002086

61. Lee JY, Jeon BS, Kim HJ, Park SS. Genetic variant of HTR2A associates with risk of impulse control and repetitive behaviors in Parkinson's disease. Parkinsonism Relat Disord. (2012) 18:76-8. doi: 10.1016/j.parkreldis.2011.08.009

62. Krishnamoorthy S, Rajan R, Banerjee M, Kumar H, Sarma G, Krishnan S, et al. Dopamine D3 receptor Ser9Gly variant is associated with impulse control disorders in Parkinson's disease patients. Parkinsonism Relat Disord. (2016) 30:13-7. doi: 10.1016/j.parkreldis.2016. 06.005

63. Cormier-Dequaire F, Bekadar S, Anheim M, Lebbah S, Pelissolo A, Krack P, et al. Suggestive association between OPRM1 and impulse control disorders in Parkinson's disease. Mov Disord. (2018) 33:187886. doi: $10.1002 / \mathrm{mds} .27519$

64. Biundo R, Weis L, Facchini S, Formento-Dojot P, Vallelunga A, Pilleri M, et al. Patterns of cortical thickness associated with impulse control disorders in Parkinson's disease. Mov Disord. (2015) 30:68895. doi: $10.1002 / \mathrm{mds} .26154$

65. Rolls ET. The orbitofrontal cortex and reward. Cereb Cortex. (2000) 10:28494. doi: 10.1093/cercor/10.3.284

66. Kraemmer J, Smith K, Weintraub D, Guillemot V, Nalls MA, CormierDequaire F, et al. Clinical-genetic model predicts incident impulse control disorders in Parkinson's disease. J Neurol Neurosurg Psychiatry. (2016) 87:1106-111. doi: 10.1136/jnnp-2015-312848

67. Vitale C, Santangelo G, Trojano L, Verde F, Rocco M, Grossi D, et al. Comparative neuropsychological profile of pathological gambling, hypersexuality, and compulsive eating in Parkinson's disease. Mov Disord. (2011) 26:830-836. doi: 10.1002/mds.23567

68. Santangelo G, Vitale C, Trojano L, Verde F, Grossi D, Barone P. Cognitive dysfunctions and pathological gambling in patients with Parkinson's disease. Mov Disord. (2009) 24:899-905. doi: 10.1002/mds.22472

69. Voon V, Reynolds B, Brezing C, Gallea C, Skaljic M, Ekanayake $\mathrm{V}$, et al. Impulsive choice and response in dopamine agonistrelated impulse control behaviors. Psychopharmacology. (2010) 207:645-59. doi: 10.1007/s00213-009-1697-y

70. Djamshidian A, Jha A, O'Sullivan SS, Silveira-Moriyama L, Jacobson C, Brown P, et al. Risk and learning in impulsive and nonimpulsive patients with Parkinson's disease. Mov Disord. (2010) 25:2203-10. doi: 10.1002/mds.23247

71. van den Heuvel OA, van der Werf YD, Verhoef KM, de Wit S, Berendse HW, Wolters E, et al. Frontal-striatal abnormalities underlying behaviours in the compulsive-impulsive spectrum. J Neurol Sci. (2010) 289:559. doi: 10.1016/j.jns.2009.08.043

72. Kobayakawa M, Tsuruya N, Kawamura M. Sensitivity to reward and punishment in Parkinson's disease: an analysis of behavioral patterns using a modified version of the Iowa gambling task. Parkinsonism Relat Disord. (2010) 16:453-7. doi: 10.1016/j.parkreldis.2010.04.011

73. Rossi M, Gerschcovich ER, de Achaval D, Perez-Lloret S, Cerquetti D, Cammarota A, et al. Decision-making in Parkinson's disease patients with and without pathological gambling. Eur J Neurol. (2010) 17:97102. doi: $10.1111 / \mathrm{j} .1468-1331.2009 .02792 . x$

74. Pineau F, Roze E, Lacomblez L, Bonnet AM, Vidailhet M, Czernecki V, et al. Executive functioning and risk-taking behavior in Parkinson's disease patients with impulse control disorders. J Neural Transm. (2016) 123:57381. doi: 10.1007/s00702-016-1549-y

75. Siri C, Cilia R, De Gaspari D, Canesi M, Meucci N, Zecchinelli AL, et al. Cognitive status of patients with Parkinson's disease and pathological gambling. J Neurol. (2010) 257:247-52. doi: 10.1007/s00415-0095301-5

76. Mack J, Okai D, Brown RG, Askey-Jones S, Chaudhuri KR, Martin A, et al. The role of self-awareness and cognitive dysfunction in Parkinson's disease with and without impulse-control disorder. J Neuropsychiatry Clin Neurosci. (2013) 25:141-9. doi: 10.1176/appi.neuropsych.12030076
77. Siri C, Cilia R, Reali E, Pozzi B, Cereda E, Colombo A, et al. Long-term cognitive follow-up of Parkinson's disease patients with impulse control disorders. Mov Disord. (2015) 30:696-704. doi: 10.1002/mds.26160

78. Pontieri FE, Assogna F, Pellicano C, Cacciari C, Pannunzi S, Morrone A, et al. Sociodemographic, neuropsychiatric and cognitive characteristics of pathological gambling and impulse control disorders NOS in Parkinson's disease. Eur Neuropsychopharmacol. (2015) 25:69-76. doi: 10.1016/j.euroneuro.2014.11.006

79. Milenkova M, Mohammadi B, Kollewe K, Schrader C, Fellbrich A, Wittfoth M, et al. Intertemporal choice in Parkinson's disease. Mov Disord. (2011) 26:2004-10. doi: $10.1002 / \mathrm{mds} .23756$

80. Joutsa J, Voon V, Johansson J, Niemela S, Bergman J, Kaasinen V. Dopaminergic function and intertemporal choice. Transl Psychiatry. (2015) 5:e491. doi: 10.1038/tp.2014.133

81. Aracil-Bolanos I, Strafella AP. Molecular imaging and neural networks in impulse control disorders in Parkinson's disease. Parkinsonism Relat Disord. (2016) 22(Suppl. 1):S101-5. doi: 10.1016/j.parkreldis.2015.08.003

82. Clark CA, Dagher A. The role of dopamine in risk taking: a specific look at Parkinson's disease and gambling. Front Behav Neurosci. (2014) 8:196. doi: $10.3389 /$ fnbeh.2014.00196

83. Schultz W, Dayan P, Montague PR. A neural substrate of prediction and reward. Science. (1997) 275:1593-9. doi: 10.1126/science.275.5306.1593

84. Ferron A, Thierry AM, Le Douarin C, Glowinski J. Inhibitory influence of the mesocortical dopaminergic system on spontaneous activity or excitatory response induced from the thalamic mediodorsal nucleus in the rat medial prefrontal cortex. Brain Res. (1984) 302:257-65. doi: 10.1016/0006-8993(84)90238-5

85. Piray P, Zeighami Y, Bahrami F, Eissa AM, Hewedi DH, Moustafa AA. Impulse control disorders in Parkinson's disease are associated with dysfunction in stimulus valuation but not action valuation. J Neurosci. (2014) 34:7814-24. doi: 10.1523/JNEUROSCI.4063-13.2014

86. Paulus MP, Hozack N, Frank L, Brown GG. Error rate and outcome predictability affect neural activation in prefrontal cortex and anterior cingulate during decision-making. Neuroimage. (2002) 15:836-46. doi: 10.1006/nimg.2001.1031

87. Diederich NJ, Goldman JG, Stebbins GT, Goetz CG. Failing as doorman and disc jockey at the same time: amygdalar dysfunction in Parkinson's disease. Mov Disord. (2016) 31:11-22. doi: 10.1002/mds.26460

88. Ambroggi F, Ishikawa A, Fields HL, Nicola SM. Basolateral amygdala neurons facilitate reward-seeking behavior by exciting nucleus accumbens neurons. Neuron. (2008) 59:648-61. doi: 10.1016/j.neuron.2008.07.004

89. Tessitore A, Santangelo G, De Micco R, Vitale C, Giordano A, Raimo $S$, et al. Cortical thickness changes in patients with Parkinson's disease and impulse control disorders. Parkinsonism Relat Disord. (2016) 24:11925. doi: 10.1016/j.parkreldis.2015.10.013

90. Yoo HB, Lee JY, Lee JS, Kang H, Kim YK, Song IC, et al. Whole-brain diffusion-tensor changes in parkinsonian patients with impulse control disorders. J Clin Neurol. (2015) 11:42-7. doi: 10.3988/jcn.2015.11.1.42

91. Petersen K, Van Wouwe N, Stark A, Lin YC, Kang H, Trujillo-Diaz P, et al. Ventral striatal network connectivity reflects reward learning and behavior in patients with Parkinson's disease. Hum Brain Mapp. (2018) 39:509-21. doi: 10.1002/hbm.23860

92. Munro CA, McCaul ME, Wong DF, Oswald LM, Zhou Y, Brasic J, et al. Sex differences in striatal dopamine release in healthy adults. Biol Psychiatry. (2006) 59:966-74. doi: 10.1016/j.biopsych.2006.01.008

93. Palermo S, Morese R, Zibetti M, Dematteis F, Sirgiovanni S, Stanziano $\mathrm{M}$, et al. Impulse control disorder and response-inhibition alterations in Parkinson's disease. A rare case of totally absent functionality of the medial-prefrontal cortex and review of literature. J Adv Res. (2017) 8:7136. doi: 10.1016/j.jare.2017.09.004

94. van Eimeren T, Pellecchia G, Cilia R, Ballanger B, Steeves TD, Houle S, et al. Drug-induced deactivation of inhibitory networks predicts pathological gambling in PD. Neurology. (2010) 75:17116. doi: 10.1212/WNL.0b013e3181fc27fa

95. Seeman P. Parkinson's disease treatment may cause impulsecontrol disorder via dopamine D3 receptors. Synapse. (2015) 69:183-9. doi: 10.1002/syn.21805 
96. Leplow B, Sepke M, Schonfeld R, Pohl J, Oelsner H, Latzko L, et al. Impaired learning of punishments in Parkinson's disease with and without impulse control disorder. J Neural Transm. (2017) 124:21725. doi: 10.1007/s00702-016-1648-9

97. Cools R, Lewis SJ, Clark L, Barker RA, Robbins TW. L-DOPA disrupts activity in the nucleus accumbens during reversal learning in Parkinson's disease. Neuropsychopharmacology. (2007) 32:180-9. doi: 10.1038/sj.npp.1301153

98. Preuschoff K, Bossaerts P, Quartz SR. Neural differentiation of expected reward and risk in human subcortical structures. Neuron. (2006) 51:38190. doi: 10.1016/j.neuron.2006.06.024

99. Chambers RA, Taylor JR, Potenza MN. Developmental neurocircuitry of motivation in adolescence: a critical period of addiction vulnerability. Am J Psychiatry. (2003) 160:1041-1052. doi: 10.1176/appi.ajp.160.6.1041

100. Claassen DO, Stark AJ, Spears CA, Petersen KJ, van Wouwe NC, Kessler $\mathrm{RM}$, et al. Mesocorticolimbic hemodynamic response in Parkinson's disease patients with compulsive behaviors. Mov Disord. (2017) 32:157483. doi: $10.1002 / \mathrm{mds} .27047$

101. O’Doherty J, Kringelbach ML, Rolls ET, Hornak J, Andrews C. Abstract reward and punishment representations in the human orbitofrontal cortex. Nat Neurosci. (2001) 4:95-102. doi: 10.1038/82959

102. Volkow ND, Fowler JS, Wang GJ. The addicted human brain viewed in the light of imaging studies: brain circuits and treatment strategies. Neuropharmacology. (2004) 47(Suppl. 1):3-13. doi: 10.1016/j.neuropharm.2004.07.019

103. Voon V, Potenza MN, Thomsen T. Medication-related impulse control and repetitive behaviors in Parkinson's disease. Curr Opin Neurol. (2007) 20:484-92. doi: 10.1097/WCO.0b013e32826fbc8f

104. Shaw MC, Forbush KT, Schlinder J, Rosenman E, Black DW. The effect of pathological gambling on families, marriages, and children. CNS Spectr. (2007) 12:615-22. doi: 10.1017/S1092852900021416

105. Roland KP, Jenkins ME, Johnson AM. An exploration of the burden experienced by spousal caregivers of individuals with Parkinson's disease. Mov Disord. (2010) 25:189-93. doi: 10.1002/mds.22939

106. Mamikonyan E, Siderowf AD, Duda JE, Potenza MN, Horn S, Stern MB, et al. Long-term follow-up of impulse control disorders in Parkinson's disease. Mov Disord. (2008) 23:75-80. doi: 10.1002/mds.21770

107. Rabinak CA, Nirenberg MJ. Dopamine agonist withdrawal syndrome in Parkinson disease. Arch Neurol. (2010) 67:5863. doi: 10.1001/archneurol.2009.294

108. Pondal M, Marras C, Miyasaki J, Moro E, Armstrong MJ, Strafella AP, et al. Clinical features of dopamine agonist withdrawal syndrome in a movement disorders clinic. J Neurol Neurosurg Psychiatry. (2013) 84:1305. doi: 10.1136/jnnp-2012-302684

109. Cunnington AL, White L, Hood K. Identification of possible risk factors for the development of dopamine agonist withdrawal syndrome in Parkinson's disease. Parkinsonism Relat Disord. (2012) 18:10512. doi: 10.1016/j.parkreldis.2012.05.012

110. Rossi PJ, Shute JB, Opri E, Molina R, Peden C, Castellanos O, et al. Impulsivity in Parkinson's disease is associated with altered subthalamic but not globus pallidus internus activity. J Neurol Neurosurg Psychiatry. (2017) 88:968-70. doi: 10.1136/jnnp-2016-315325

111. Lhommee E, Boyer F, Wack M, Pelissier P, Klinger H, Schmitt E, et al. Personality, dopamine, and Parkinson's disease: insights from subthalamic stimulation. Mov Disord. (2017) 32:1191-200. doi: 10.1002/mds.27065

112. Lhommee E, Klinger H, Thobois S, Schmitt E, Ardouin C, Bichon A, et al. Subthalamic stimulation in Parkinson's disease: restoring the balance of motivated behaviours. Brain. (2012) 135:1463-77. doi: 10.1093/brain/aws078

113. Adams WK, Vonder Haar C, Tremblay M, Cocker PJ, Silveira MM, Kaur $\mathrm{S}$, et al. Deep-brain stimulation of the subthalamic nucleus selectively decreases risky choice in risk-preferring rats. eNeuro. (2017) 4:e0094-17. doi: 10.1523/ENEURO.0094-17.2017

114. Merola A, Romagnolo A, Rizzi L, Rizzone MG, Zibetti M, Lanotte $\mathrm{M}$, et al. Impulse control behaviors and subthalamic deep brain stimulation in Parkinson disease. J Neurol. (2017) 264:40-48. doi: 10.1007/s00415-016-8314-X

115. Ardouin C, Voon V, Worbe Y, Abouazar N, Czernecki V, Hosseini $\mathrm{H}$, et al. Pathological gambling in Parkinson's disease improves on chronic subthalamic nucleus stimulation. Mov Disord. (2006) 21:19416. doi: $10.1002 / \mathrm{mds} .21098$

116. Castrioto A, Funkiewiez A, Debu B, Cools R, Lhommee E, Ardouin $\mathrm{C}$, et al. Iowa gambling task impairment in Parkinson's disease can be normalised by reduction of dopaminergic medication after subthalamic stimulation. J Neurol Neurosurg Psychiatry. (2015) 86:186-90. doi: 10.1136/jnnp-2013-307146

117. Knobel D, Aybek S, Pollo C, Vingerhoets FJ, Berney A. Rapid resolution of dopamine dysregulation syndrome (DDS) after subthalamic DBS for Parkinson disease (PD): a case report. Cogn Behav Neurol. (2008) 21:1879. doi: 10.1097/WNN.0b013e318185e6e2

118. Alberts JL, Voelcker-Rehage C, Hallahan K, Vitek M, Bamzai R, Vitek JL. Bilateral subthalamic stimulation impairs cognitive-motor performance in Parkinson's disease patients. Brain. (2008) 131:334860. doi: 10.1093/brain/awn238

119. Lim SY, O'Sullivan SS, Kotschet K, Gallagher DA, Lacey C, Lawrence AD, et al. Dopamine dysregulation syndrome, impulse control disorders and punding after deep brain stimulation surgery for Parkinson's disease. J Clin Neurosci. (2009) 16:1148-52. doi: 10.1016/j.jocn.2008.12.010

120. Moum SJ, Price CC, Limotai N, Oyama G, Ward H, Jacobson C, et al. Effects of STN and GPi deep brain stimulation on impulse control disorders and dopamine dysregulation syndrome. PLoS ONE. (2012) 7:e29768. doi: 10.1371/journal.pone.0029768

121. Smeding HM, Goudriaan AE, Foncke EM, Schuurman PR, Speelman JD, Schmand B. Pathological gambling after bilateral subthalamic nucleus stimulation in Parkinson disease. J Neurol Neurosurg Psychiatry. (2007) 78:517-9. doi: 10.1136/jnnp.2006.102061

122. De la Casa-Fages B, Grandas F. Dopamine dysregulation syndrome after deep brain stimulation of the subthalamic nucleus in Parkinson's disease. $J$ Neurol Sci. (2012) 312:191-3. doi: 10.1016/j.jns.2011.08.014

123. Le Jeune F, Peron J, Grandjean D, Drapier S, Haegelen C, Garin E, et al. Subthalamic nucleus stimulation affects limbic and associative circuits: a PET study. Eur J Nucl Med Mol Imaging. (2010) 37:151220. doi: 10.1007/s00259-010-1436-y

124. Castrioto A, Lhommee E, Moro E, Krack P. Mood and behavioural effects of subthalamic stimulation in Parkinson's disease. Lancet Neurol. (2014) 13:287-305. doi: 10.1016/S1474-4422(13)70294-1

125. Thomas A, Bonanni L, Gambi F, Di Iorio A, Onofrj M. Pathological gambling in Parkinson disease is reduced by amantadine. Ann Neurol. (2010) 68:4004. doi: 10.1002/ana.22029

126. Kashihara K, Imamura T. Amantadine may reverse punding in Parkinson's disease-observation in a patient. Mov Disord. (2008) 23:129-30. doi: 10.1002/mds.21780

127. Cera N, Bifolchetti S, Martinotti G, Gambi F, Sepede G, Onofrj $\mathrm{M}$, et al. Amantadine and cognitive flexibility: decision making in Parkinson's patients with severe pathological gambling and other impulse control disorders. Neuropsychiatr Dis Treat. (2014) 10:1093-101. doi: 10.2147/NDT.S54423

128. Weintraub D, Sohr M, Potenza MN, Siderowf AD, Stacy M, Voon $\mathrm{V}$, et al. Amantadine use associated with impulse control disorders in Parkinson disease in cross-sectional study. Ann Neurol. (2010) 68:9638. doi: 10.1002/ana.22164

129. Todorova A, Samuel M, Brown RG, Chaudhuri KR. Infusion therapies and development of impulse control disorders in advanced Parkinson disease: clinical experience after 3 years' follow-up. Clin Neuropharmacol. (2015) 38:132-4. doi: 10.1097/WNF.00000000000 00091

130. Catalan MJ, de Pablo-Fernandez E, Villanueva C, Fernandez-Diez S, LapenaMontero T, Garcia-Ramos R, et al. Levodopa infusion improves impulsivity and dopamine dysregulation syndrome in Parkinson's disease. Mov Disord. (2013) 28:2007-10. doi: 10.1002/mds.25636

131. Rotondo A, Bosco D, Plastino M, Consoli A, Bosco F. Clozapine for medication-related pathological gambling in Parkinson disease. Mov Disord. (2010) 25:1994-5. doi: 10.1002/mds.23177

132. Hardwick A, Ward H, Hassan A, Romrell J, Okun MS. Clozapine as a potential treatment for refractory impulsive, compulsive, and punding behaviors in Parkinson's disease. Neurocase. (2013) 19:58791. doi: $10.1080 / 13554794.2012 .713490$ 
133. Bonfils NA, Benyamina A, Aubin HJ, Luquiens A. Clozapine use for refractory impulse control disorders in Parkinson's disease: a case report. Psychopharmacology. (2015) 232:3677-9. doi: 10.1007/s00213-015-4048-1

134. Nardone R, De Blasi P, Holler Y, Christova M, Tezzon F, Trinka E, et al. Repetitive transcranial magnetic stimulation transiently reduces punding in Parkinson's disease: a preliminary study. J Neural Transm. (2014) 121:26774. doi: 10.1007/s00702-013-1100-3

135. Okai D, Askey-Jones S, Samuel M, O'Sullivan SS, Chaudhuri KR, Martin A, et al. Trial of CBT for impulse control behaviors affecting Parkinson patients and their caregivers. Neurology. (2013) 80:7929. doi: 10.1212/WNL.0b013e3182840678

136. Sriram A, Ward HE, Hassan A, Iyer S, Foote KD, Rodriguez $\mathrm{RL}$, et al. Valproate as a treatment for dopamine dysregulation syndrome (DDS) in Parkinson's disease. J Neurol. (2013) 260:521-7. doi: 10.1007/s00415-012-6669-1
137. Kraus SW, Etuk R, Potenza MN. Current pharmacotherapy for gambling disorder: a systematic review. Expert Opin Pharmacother. (2020) 21:28796. doi: 10.1080/14656566.2019.1702969

Conflict of Interest: The authors declare that the research was conducted in the absence of any commercial or financial relationships that could be construed as a potential conflict of interest.

Copyright (c) 2021 Zhang, Wang, Feng, Fekete, Jankovic and Wu. This is an openaccess article distributed under the terms of the Creative Commons Attribution License (CC BY). The use, distribution or reproduction in other forums is permitted, provided the original author(s) and the copyright owner(s) are credited and that the original publication in this journal is cited, in accordance with accepted academic practice. No use, distribution or reproduction is permitted which does not comply with these terms. 